\title{
A pesquisa multicultural como eixo na formação docente: potenciais para a discussão da diversidade e das diferenças*
}

\author{
Ana Canen**
}

\section{Resumo}

presente artigo argumenta que a compreensão da pesquisa como fenômeno multicultural pode tornar a articulação ensino-pesquisa mais impactante na formação de professores, Desenvolve o argumento, propondo quatro dimensões centrais nessa perspectiva: a compreensão dos futuros professores e professores formadores como identidades culturais plurais de pesquisadores em ação; o incentivo às discussões dos temas educacionais em termos de vozes silenciadas e representadas, analisando tensões entre universalismo e valorização da diversidade; a apresentação dos professores em formação a metodologias plurais de pesquisa; a análise das identidades institucionais ou organizacionais onde se processa a formação docente e sua articulação à perspectiva de pesquisa, problematizando relações desiguais de poder e lutando para que essas instituições se constituam em instituições ou organizações multiculturais.

Palavras-chave: Formação de professores. Multiculturalismo. Pesquisa multicultural.

\section{Multicultural research as a backbone of teacher's formation: potential topics for the discussion about diversity and difference Abstract}

This paper argues that the comprehension of the research as a multicultural phenomenon can give the link teach-research a great significance to teachers formation. The article develops this idea by suggesting four main dimensions on this viewpoint: first, the conception of future teachers and teacher educators as researchers in action of plural cultural identity; second, the encouragement of discussions about educational themes in terms of silenced and represented voices, analyzing tensions between universal and diversity value; third, the expose of the future teachers to plural research methodologies; and finally, the analysis of the institution or organization identity where teachers formation happens, showing the proble-

\footnotetext{
"Versão preliminar deste trabalho foi apresentada na Sessão Especial : Diversidade, Diferença e Formação Docente, $30^{a}$ Reunião Anual da ANPEd, outubro de 2007, Caxambu, Minas Gerais

** PhD em Educação, University of Glasgow; Professora da Universidade Federal do Rio de Janeiro; Pesquisadora do CNPq.E-mail: acanen@globo.com
} 
ms related to unequal power relations and trying to make these institutions become multicultural organizations.

Keywords: Teacher education. Multiculturalism. Multicultural research.

\section{La investigación multicultural como eje de la formación de profesores: potenciales para las discusiones de la diversidad y de las diferencias Resumen}

El artículo discute que la comprensión de la investigación como un fenómeno multicultural puede llevar a una articulación entre educación-investigación de más impacto en la formación de profesores. Este trabajo desenvuelve la discusión proponiendo cuatro dimensiones centrales: la comprensión de los futuros profesores y de los profesores formadores como identidades culturales plurales de investigadores en acción; el incentivo a las discusiones de los temas educacionales en término de voces silenciadas y representadas, analizando las tensiones entre universalismo y valorización de la diversidad; la presentación de la metodología plural de investigación a los profesores en formación; el análisis de las identidades institucionales o organizacionales donde se construye la formación del profesor y su articulación a la perspectiva de investigación, colocando como problema las relaciones desiguales de poder y luchando para que esas instituciones se organicen en instituciones o organizaciones multiculturales.

Palabras clave: Formación de profesores. Multiculturalismo. Investigación multicultural.

\section{Introdução}

Discutir o papel da pesquisa em uma perspectiva multicultural como eixo na formação de professores, analisando seu potencial para a discussão da diversidade e das diferenças, é o foco do presente artigo. Neste sentido, torna-se relevante delinear componentes do eixo acima, em termos da compreensão das identidades do pesquisador e dos sujeitos pesquisados, das metodologias e dos temas e conteúdos trabalhados no ensino e na pesquisa, em uma perspectiva multicultural.

De fato, muito se tem discutido sobre o papel da pesquisa na formação de professores. Autores como Lüdke (2001) e André (2001), por exemplo, têm demonstrado a força da idéia do professor-pesquisador, do profissional reflexivo, que problematiza sua prática, refletindo criticamente sobre a mesma e buscando caminhos viabilizadores de transformações. Ao mesmo tempo, entretanto, ressaltam os desafios para a concretização desse ideal, desafios estes referentes a fatores tais como a própria compreensão do conceito de pesquisa e formas variadas pelas quais se pensa sobre sua articulação à prática de formação docente.

presente artigo defende que o trabalho abstrato, essencializado e pseudo-universal do conceito de pesquisa pouco contribui para a formação do professor-pesquisador apto a refletir criticamente sobre sua prática e sobre o contexto social, político e cultural mais amplo onde se insere. Argumenta que a compreensão da pesquisa como fenômeno 
multicultural pode contribuir para efetivamente tornar a articulação ensino-pesquisa mais impactante na formação de professores, apontando quatro dimensões centrais nessa perspectiva: a) a compreensão dos futuros professores e professores formadores como pesquisadores em ação, sujeitos portadores de identidades culturais singulares, inseridos em contextos culturais, organizacionais e discursivos específicos; b) o incentivo às discussões dos temas educacionais de forma problematizadora, mobilizadora do desenvolvimento de atitudes de pesquisa que ressaltem as tensões entre pretensões à universalidade e à diversidade cultural, bem como que questionem preconceitos e identidades silenciadas, nos mesmos; c) a apresentação dos professores em formação a metodologias plurais de pesquisa, entendidas como formas de se proceder a um mergulho na realidade que, no entanto, será sempre filtrado pelo olhar do professor-pesquisador, produtor de narrativas singulares sobre esta realidade; d) a análise das identidades institucionais ou organizacionais onde se processa a formação docente e sua articulação à perspectiva de pesquisa, problematizando relações desiguais de poder e lutando para que essas instituições se constituam em organizações multiculturais(CANEN, A. G.; CANEN, A., 2005b).

artigo desenvolverá as quatro dimensões acima, discutindo os impactos e potenciais da perspectiva multicultural a partir delas concebida, para a articulação ensino e pesquisa em abordagens críticas e transformadoras, no âmbito da formação de professores.

\section{Professores como pesquisadores em ação: pensando nos sujeitos plurais no ensino e na pesquisa}

Em recentes trabalhos, frutos de pesquisas desenvolvidas (CANEN, A., 2007; CANEN, A.; OLIVEIRA, 2002; CANEN, A.; SANTOS, 2006; CANEN, A.; XAVIER, G. P. M., 2005; CANEN, A.; ANDRADE, 2005), problematizamos a visão de pesquisa que, muitas vezes, impregna os cursos de formação de professores. Tal visão é, freqüentemente, limitada à compreensão de modelos de construção de projetos de pesquisa, enfatizando o aspecto instrumental em detrimento da discussão das finalidades, dos impactos e da dimensão cultural e política da pesquisa em educação. Também fica faltando incorporar a dimensão da pesquisa no próprio corpo da formação de professores, muitas vezes deixando-se para falar sobre a mesma apenas em disciplinas específicas de Metodologia de Pesquisa ou na preparação para a formulação de monografias de conclusão de curso.

A compreensão do pesquisador como não-neutro, como portador de identidade cultural, étnica, racial, religiosa, de gênero e outros fatores tem sido por nós enfatizada, reforçando o que Denzin e Lincoln (2000) defendem como a visualização do pesquisador como sujeito multicultural, que é influenciado por sua história de vida, seus pertencimentos identitários e pelas relações estabelecidas em seu campo de atuação e de pesquisa. Trabalhar com a pesquisa no âmbito da formação de professores poderia, nesta visão, incorporar o papel do futuro professor como pesquisador em ação, problematizando, em primeiro lugar, a pseudo-neutralidade com que costuma ser interpretado, tanto no ato de ensinar como no de pesquisar.

A primeira dimensão no trabalho da formação de professores-pesquisadores em uma visão multicultural passa pela sensibilização à diversidade cultural dos profes- 
sores-formadores-autores-pesquisadores, que constroem/transmitem o conhecimento na área educacional, assim como dos futuros professores e dos estudantes com que vão interagir. Tal visão leva à discussão dos paradigmas que movem o professorpesquisador, variando desde perspectivas mais funcionalistas, neo-positivistas, que defendem a possibilidade de acesso ao real por este professor-pesquisador, passando por outras de cunho mais crítico, que preconizam a necessidade de compromisso político com a transformação da realidade e chegando a paradigmas ligados a perspectivas pós-modernas, construtivistas sociais, que movem professores- pesquisadores no sentido de focalizarem suas atenções nos discursos que circulam nos ambientes em estudo e nas relações desiguais de poder que resultam em ênfases ou omissões aí presentes.

Esse primeiro nível de discussão remete, por um lado, à estreita vinculação entre a forma pela qual um mesmo tema de pesquisa pode ser desenvolvido e problematizado em perspectivas plurais. É interessante, nessa perspectiva, a observação, feita por Fávero e Segenreich (2004, p. 82), citando o historiador Edward Carr, a propósito do impacto do pesquisador sobre o objeto pesquisado, no contexto da pesquisa historiográfica: "os fatos não falam por si [...] mas falam quando o pesquisador os aborda - pois é ele quem decide quais os fatos que vêm à cena e em que ordem ou contexto [...]". Estreitamente ligada a esse aspecto, a visão multicultural de pesquisa leva à necessidade de valorização das formas diferenciadas de se realizar pesquisa, respeitando-se os paradigmas dos pesquisadores e os critérios de rigor e relevância inerentes àqueles paradigmas.

Optar por uma só forma de realizar pesquisa, de levantar temas ou problematizar a realidade educacional pode significar o retorno ao "pensamento único", tão questionado durante o processo de evolução da pesquisa em educação, que vinculava o caráter científico apenas aos estudos desenvolvidos sob a égide do positivismo lógico e da metodologia quantitativa.

A pluralidade paradigmática defendida pelo olhar multicultural sobre a pesquisa responde à complexidade dos problemas que nos desafiam na área educacional em três perspectivas. Em primeiro lugar, essa perspectiva valoriza as contribuições dos diferentes pontos de vista no enfrentamento desses problemas, desafiando dogmatismos ou visões estáticas, marcadas ideologicamente pelo preconceito com relação às diferenças e pelo afã de imposição de visões uniformes sobre a realidade. Isso faz com que os textos que ministramos em nossas disciplinas de formação docente possam ser discutidos, problematizados, em termos das visões de mundo que os impregnam, dos paradigmas que movem os autores, contextualizando suas contribuições e, sempre que possível, trazendo pontos de vista alternativos que problematizem aquelas visões ou que estejam situados em paradigmas diferentes.

Em segundo lugar, esta visão pluralística de paradigmas que movem professorespesquisadores é relevante na medida em que, na linha defendida por Charlot (2006), desafia "panelinhas teóricas" e chama, para si, o conceito de hibridização ou mestiçagem, que caracteriza linhas teóricas e campos que matizam, mesclam e sintetizam contribuições de áreas diversas em perspectivas trans e interdisciplinares, rompendo 
barreiras curriculares (CANEN, A.; CANEN, A. G., 2005a). Isso significa, ainda utilizando a ilustração acima de discussão de textos nas aulas de formação de professores, trabalhar com novos campos, novos olhares, sínteses culturais criativas e mestiças pelas quais os problemas da educação brasileira são analisados por autores nacionais e internacionais, em nosso campo, para além dos olhares das disciplinas mais convencionais.

Em terceiro lugar, tal perspectiva permite ao professor-pesquisador compreender a importância da valorização da diversidade cultural, do embate entre posturas e paradigmas diferentes na interpretação do real. Propicia a oportunidade de compreender a necessidade de combate ao pensamento único, bem como a importância em se ter acesso a pontos de vista culturais plurais e, muitas vezes, contraditórios, que perfazem as narrativas sobre este real.

Na formação de professores, tal olhar representa um eixo que muito tem a contribuir para a reflexão crítica sobre a própria pesquisa, levando estudantes e futuros professores a identificarem âncoras teóricas e influências identitárias do pesquisador e do professor nos temas, problematizações e caminhos percorridos. Auxilia, também, futuros professores a pensarem em suas próprias identidades culturais e os impactos das mesmas em suas escolhas e pertencimentos, no cotidiano das relações estabelecidas nas instituições de ensino brasileiras. Prepara-os para a desconfiança de discursos que buscam silenciar suas identidades. Sensibiliza-os para o combate àqueles que apresentam, travestida de cientificidade, a defesa de linhas teóricas e campos apresentados como "puros" mas que embutem, na verdade, preconceitos contra campos teóricos mestiços (CHARLOT, 2006) - tais como o multiculturalismo e a própria educação, centrais no enfrentamento de problemas cada vez mais complexos no mundo contemporâneo.

Em recente trabalho sobre o significado de pesquisa atribuído por professorespesquisadores-formadores (CANEN, A.; ANDRADE, 2005), fica clara a pluralidade de visões epistemológicas, ontológicas e metodológicas que configuram a pesquisa em educação, bem como a necessidade, em uma formação docente crítica, de discussão das possibilidades paradigmáticas que se abrem para o pesquisador, em sintonia com sua identidade cultural singular e com o contexto cultural em que se insere seu estudo. Ao mesmo tempo, em outra pesquisa realizada (CANEN, A.; XAVIER, G. P. M., 2005), analisou-se o conceito de pesquisa presente nas Diretrizes Curriculares Nacionais para a formação de professores, identificando-se potenciais e lacunas no que se refere a uma visão multicultural da pesquisa em educação.

Trata-se, pois, esta primeira dimensão - a compreensão da pluralidade de sujeitos e de suas visões de mundo no ato de ensinar e pesquisar - uma primeira aproximação para se relativizar verdades e dogmas, na formação de professores, bem como de se questionar argumentos de autoridade, muitas vezes presentes em textos e materiais com que trabalhamos no contexto desta formação. Esta dimensão permite que se trabalhe em uma perspectiva de articulação ensino e pesquisa que problematize conteúdos ensinados, identifique paradigmas, contextos e crenças plurais que movem autores e pesquisadores. Permite trabalhar o ensino e a pesquisa em uma 
perspectiva de valorização da diversidade cultural, em uma visão de educação igualmente voltada à valorização do plural e do diverso. Compreender, pois, o pesquisador como sujeito multicultural, que se afina com visões epistemológicas e ontológicas inerentes a paradigmas plurais de pesquisa, significa superar a ingenuidade sobre uma falsa neutralidade ou universalidade no ato de pesquisar e de ensinar, condição central para a abertura para culturas e visões plurais, presentes na escola.

\section{O olhar multicultural sobre temas, metodologias e instituições da formação docente: perspectivas, tensões o desafio a preconceitos}

A visão multicultural da pesquisa na formação de professores, para além das considerações acima, implica pensar-se nas três outras dimensões apontadas anteriormente como constitutivas dessa formação, quais sejam: os temas educacionais, as metodologias de pesquisa no mergulho na realidade das escolas e o papel das instituições ou organizações multiculturais (CANEN, A. G.; CANEN, A., 2005b) no fomento à pesquisa e à pluralidade cultural, no contexto dessa formação.

No que se refere aos temas e problemas que informam o desenvolvimento de pesquisas-segunda dimensão apontada no presente trabalho, no âmbito da formação de professores - temos defendido (CANEN, A., 2004) que a pesquisa em uma abordagem multicultural pode eleger, de um lado, temas educacionais mais voltados às questões relativas ao desafio a preconceitos e valorização da diversidade étnica, racial, de gênero e outras; de outro, pode significar um olhar sobre as tensões que cercam temas mais convencionais na educação, tais como o currículo e a avaliação.

No caso de temas voltados à valorização da diversidade cultural, étnica, racial, religiosa, de gênero e outras, estes podem ser trabalhados por intermédio de textos e materiais que destaquem em que medida as identidades plurais têm sido contempladas em abordagens teóricas, em práticas pedagógicas cotidianas e em políticas educacionais no Brasil e em outros países. Nesse contexto, a discussão do impacto de ações afirmativas na Educação, os dilemas de grupos identitários como negros, indígenas e outros no cotidiano escolar e nas políticas educacionais, estudos de caso que ilustrem desafios, no cotidiano do professor, em lidar com a pluralidade cultural na escola e com o desafio a preconceitos, são alguns exemplos.

Para além desse tipo de abordagem, o multiculturalismo pode representar uma lente que auxilia no diagnóstico de tensões entre visões que se pretendem mais "universalistas" e outras mais "relativistas" na abordagem de temas mais convencionais da educação. Em outras palavras, essas tensões dão-se no contexto das discussões entre universalismo e relativismo, traduzidas, por exemplo, na análise de propostas e políticas que buscam apresentar parâmetros ou diretrizes comuns em educação (por exemplo, diretrizes curriculares nacionais, parâmetros curriculares nacionais, sistemas de avaliação de larga escala) e sua convivência com outras que valorizam a diversidade, a pluralidade (currículos locais, processos de avaliação diagnóstica e formativa, e assim por diante). 
Como ilustração, em artigo recente (AGUIAR; CANEN, A., 2007), analisou-se o contexto dos desafios da avaliação em uma instituição naval, a partir do olhar multicultural, verificando-se tensões entre critérios comuns, baseados na identidade organizacional naval, e aqueles que buscavam abertura para a valorização das atuações dos diferentes atores institucionais. Da mesma forma, em outro trabalho (CANEN, A., 2005), analisamos as tensões e hibridizações presentes na avaliação em seus diversos níveis (de aprendizagem, institucional e de sistemas), discutindo tais tensões no bojo de projetos nacionais e suas relações com projetos educacionais próprios e formas singulares, plurais de desenvolvimento da avaliação. $O$ olhar multicultural busca, também, analisar ênfases e omissões no currículo (CANEN, A.; MOREIRA, 2001), inquirindo sobre as vozes aí representadas e aquelas silenciadas, nessas áreas em estudo.

Dessa forma, o olhar multicultural sobre temas da formação de professores pode torná-los objetos de pesquisa, ao invés de serem apresentados de forma estática ou coloridos por opções ideológicas que impedem a análise das tensões e hibridizações sofridas na tradução de políticas e opções teóricas educacionais em práticas. Tal dimensão pode favorecer sinergias e hibridizações com outros campos, na busca de soluções para os complexos problemas educacionais. Permite a futuros professores uma atitude de pesquisa que envolve a problematização de temas educacionais, em termos de possibilidades e limites para a incorporação da diversidade cultural em políticas e práticas educacionais.

Para além da visualização da perspectiva multicultural em termos dos paradigmas plurais que movem os pesquisadores, bem como das temáticas e problematizações da pesquisa por eles desenvolvidas (as duas dimensões anteriormente tratadas por nós), pensar multiculturalmente sobre pesquisa vai ao encontro de análise de metodologias que têm questionado o poder do pesquisador e das fontes documentais de fornecerem um retrato "fiel" da realidade pesquisada - terceira dimensão proposta no presente artigo, como constitutiva da formação de professores em uma perspectiva multicultural. $O$ contato do futuro professor com metodologias de pesquisa, tanto quantitativas como qualitativas, em uma perspectiva multicultural, significa vencer preconceitos arraigados com relação a ambos os tipos metodológicos, na medida em que se demonstram não só limites e possibilidades presentes nos dois caminhos, como também sua pertinência aos objetos específicos de pesquisa e a influência do professor pesquisador em todo o processo. Colocar futuros professores em contato com metodologias de pesquisa e conduzir atividades que demandem a realização de investigações de campo e discussão de caminhos metodológicos empreendidos, em uma perspectiva multicultural, permite o desenvolvimento de professores pesquisadores que questionam a apreensão do real e sua tradução nos relatos de pesquisa, tradução esta sempre vinculada às identidades culturais e às opções paradigmáticas.

Podemos dar um exemplo dessa abordagem no caso da metodologia da pesquisa histórico-documental. Tal metodologia pode ser apresentada no contexto de trabalhos propostos às turmas de formação de professores, que demandem, suponhamos, uma investigação sobre os caminhos que levaram à constituição do currículo naquela instituição. Futuros professores podem ser incentivados a traçar documentos que comprovem a construção das opções curriculares, tais como as grades, as atas de reuniões em 
que decisões foram tomadas com relação ao currículo, assim como entrevistar atores que participaram do processo. Neste caso, a perspectiva multicultural de apresentação e discussão metodológica permite compreender as diferentes perspectivas e vozes que constroem a história. Duas vertentes neste trabalho podem ser ilustradas. De um lado, a busca das vozes silenciadas e daquelas autorizadas, presentes nos discursos que imbuem os documentos (no nosso exemplo, isto significaria analisarem-se as diferentes opções, quem as defendia, que perspectivas acabaram por impor-se, o que significou este resultado, em termos de ênfases e omissões curriculares); de outro, o interesse por histórias orais, histórias de vida e fontes documentais plurais, muitas das quais pessoais, de modo a levar em conta as narrativas multiculturais que constroem a história (no nosso exemplo, isso significaria entrevistar os atores, situados em diferentes perspectivas, que participaram da história do currículo daquela instituição).

Nesse exemplo da pesquisa histórico-documental como caminho metodológico, o conceito de história é substituído pelo de narrativa historiográfica, buscando-se perceber o lugar dos grupos identitários em sua construção, em termos de sua presença ou invisibilidade. Uma ilustração desse tipo de abordagem é fornecida por Fonseca (2007), que almeja apreender, em seu trabalho, "a forma como os negros vêm sendo tratados nas narrativas da historiografia educacional". No referido artigo, Fonseca analisa publicações na área, identificando a ausência ou presença do negro nas mesmas, focalizando, particularmente, o caso da documentação com relação à história da educação em Minas Gerais, concluindo que a questão racial está presente a partir da documentação censitária, relativa à instrução pública, bem como nos relatos de viajantes, com um viés que parece tornar invisível ou mesmo "estranha" a presença do negro. Conclui que o processo de renovação da historiografia educacional "não avançou no sentido de desnaturalizar o lugar tradicionalmente ocupado pelos negros, tampouco construiu um padrão de narrativa que os incorporasse à história da educação" (FONSECA, 2007, p. 44).

Da mesma forma, a análise de fontes documentais alternativas, não oficiais, passa a ser valorizada, uma vez que permite o acesso às narrativas historiográficas feitas a partir de fontes tais como a literatura, a prosa, os relatos, matérias jornalísticas e outras, de cunho pessoal, destacando-se diários, fotos, e assim por diante. Tais narrativas revelam vozes plurais de identidades individuais e coletivas, não hegemônicas e, portanto, longe de terem sido incorporadas às visões oficiais da história. É o caso, por exemplo, de trabalho realizado por nós (CANEN, A.; XAVIER, L. N., 2000, p. 63), que buscou "superar a visão estática da memória nacional para que se viabilize a expressão de diversas vozes na construção da história nacional, incluindo as memórias de grupos e indivíduos diversificados".

De fato, o referido estudo focalizou o registro de memória preservado em uma obra específica - "Os meus romanos: alegrias e tristezas de uma educadora alemã no Brasil", de Ina Von Binzer (1994) - que reúne cartas da jovem governanta alemã, que veio trabalhar no Brasil entre 1881 e 1883, período que antecedeu a abolição da escravatura. Argumentamos, no referido trabalho (BINZER, 1994 apud CANEN, A.; XAVIER, L. N., 2000, p. 64), que o mergulho sobre essa fonte documental de cunho pessoal permite perceber "o potencial que as fontes históricas não convencionais, 
entre elas as memórias pessoais ou de grupos sociais, representam para a compreensão da história da educação brasileira" e, de outro, "aprofunda dimensões e contradições envolvidas em processos de (re)construção identitária, a partir do olhar dos sujeitos que dela participam". Neste sentido, o referido estudo mostrou o caso de uma educadora estrangeira, que chegou ao Brasil ainda presa a visões fortemente marcadas por estereótipos e por perspectivas etnocêntricas. Revelou que, "no decorrer de sua estada no país, [esta] passou a reconfigurar sua identidade, em processos de hibridização narrados em suas cartas", o que sugeriu a relevância do multiculturalismo na perspectiva de análise historiográfica e a importância das fontes documentais plurais nessa visão.

Um outro exemplo pode ser dado a partir de pesquisas na metodologia de estudos de caso de cunho etnográfico, tais como a desenvolvida por Canen e Oliveira (2002), em que estratégias desenvolvidas no cotidiano escolar de uma professora de Ciências revelaram formas pelas quais trabalhava o conteúdo daquela disciplina em perspectivas anti-racistas, por meio de crítica cultural (possibilidade dada aos alunos de compreender, de forma crítica, formas de perpetuação do preconceito, de modo a desafiálo), ancoragem social de conteúdos (vinculação dos conteúdos a perspectivas sociológicas e históricas, de modo a compreender a incidência de condições desiguais em casos aparentemente resolvidos pelo campo disciplinar; no caso em pauta, a ancoragem social do tema "pele" era realizada conectando-se o tema, de cunho biológico, a análises de textos que falavam do racismo e do preconceito com relação à cor da pele) e hibridização cultural (possibilidade de trabalhar os assuntos por meio de olhares e metodologias diversificadas, para além do "purismo" disciplinar).

A partir das ilustrações acima, fica evidente que a perspectiva multicultural de análise historiográfica, de estudos de caso e outras metodologias de pesquisa pode avançar no sentido de possibilitar a formação do professor pesquisador apto a analisar criticamente as metodologias de pesquisa e as fontes documentais em termos das narrativas aí produzidas, bem como capaz de inquirir sobre a invisibilidade ou o preconceito que atinge identidades étnicas, raciais, religiosas e outras, por meio da imersão nos contextos e pela participação ativa na produção de pesquisas, no seu contexto de formação.

Finalmente, a quarta dimensão a que nos referimos no presente trabalho como constitutiva da perspectiva multicultural da pesquisa na formação de professores significa promover o debate e a compreensão das identidades institucionais do campo estudado e que informam a construção da realidade, para além dos discursos homogeneizadores. A busca pela análise da identidade institucional ou organizacional do contexto em que se dá a formação de professores torna-se, neste prisma, objeto de pesquisa, de modo a articular a visão multicultural com o entorno específico em que circula o professor-pesquisador.

Nesse sentido, analisar a identidade institucional ou organizacional em que se desenvolve a formação, incluindo, aí, o contexto das parcerias entre instituições diversas tais como as escolas, as Secretarias de Educação e as Instituições de Ensino Superior (CANEN, A.; SANTOS, 2006) torna-se relevante, na perspectiva multicultu- 
ral de formação de professores. Isso porque, nessa perspectiva, trata-se de verificar em que medida se trabalha com instituições ou organizações multiculturais (CANEN, A. G.; CANEN, A., 2005b), que estão abertas à pluralidade e à diversidade ou, ao contrário, são impermeáveis às mesmas. Tal visão permite a futuros professores um olhar problematizador sobre as culturas institucionais, buscando a sensibilização para formas pelas quais relações de poder assimétricas possam estar perpetuando-se no contexto institucional, bem como incentivando-os a inquirir sobre mecanismos de exclusão ou de silenciamento de identidades, de modo a contribuir, de forma ativa e participativa no desafio aos mesmos.

Tal aspecto torna-se central, uma vez que a pesquisa na formação docente, em uma perspectiva multicultural, não deve ser entendida apenas como objeto de estudo, mas sim como possibilidade de engajar futuros professores em movimentos de busca por ambientes de pesquisa que valorizam a pluralidade cultural, que são permeáveis ao diálogo das diferenças, incentivadores de paradigmas e vozes diversificadas e, acima de tudo, desafiadores de visões congeladas e uniformizadas do ato de ensinar e de pesquisar e dos temas e referenciais teóricos de pesquisa o que ocorrerá apenas em ambientes institucionais questionadores de quaisquer tentativas de imposição de modo único de pensamento e de formas homogêneas de se tratar a pesquisa em educação.

\section{Conclusões}

presente trabalho discutiu o papel da pesquisa na formação de professores, em uma perspectiva multicultural. Defendeu que tal perspectiva contribui para o preparo de docentes aptos a analisarem criticamente o impacto de seus valores e paradigmas sobre os temas educacionais, questionando tensões entre visões universalistas e relativistas aí presentes, bem como trilhando metodologias de pesquisa e analisando fontes documentais em termos das identidades aí representadas ou silenciadas, bem como buscando formas pelas quais a pluralidade cultural possa ser representada. Essa perspectiva promove, pois, a sensibilização para a diversidade cultural, incluindo a pluralidade de formas de se fazer pesquisa, de promover o ensino e a aprendizagem e de interpretar o real.

As quatro dimensões apresentadas no artigo representam possíveis vias de formação docente pela pesquisa multiculturalmente concebida. Compreender a pluralidade de paradigmas que informam autores e pesquisadores, bem como tensões presentes nos temas educacionais mais convencionais entre princípios pretensamente universais e a diversidade cultural, assim como a compreensão das metodologias de pesquisa como trilhas plurais de busca de conhecimento das realidades educacionais e, por fim, analisar criticamente ambientes institucionais e organizacionais onde se desenvolve a formação de modo a perceber modos de silenciamento e exclusão e desafiá-los, foram propostos como caminhos possíveis, para que superemos uma formação docente muitas vezes baseada em visões educacionais monoculturais e avessas a desafios.

Trata-se de incorporar a pesquisa na formação de professores que discuta não apenas conteúdos e metodologias mas, sobretudo, que mergulhe no contexto cultural 
em que são produzidos os mesmos, inquirindo-se sobre relações de poder que resultam na incorporação, em seu bojo, de algumas vozes e no silenciar de outras. Neste sentido, o contexto da formação de professores passa a ser visto em termos das formas discursivas que aí circulam, bem como modos de sua produção, impactos que buscam ênfases e omissões que perpetuam.

Entender a formação docente como plural, construída por narrativas e pontos de vista diversificados, ajuda futuros professores a situarem a produção do conhecimento em seu caráter de construção, superando uma visão essencializada e universalizada do ensino e da pesquisa, e entendendo-os como complexos, plurais e plurivocais. Argumentamos, finalmente, que tal perspectiva florescerá em ambientes em que a identidade institucional configure-se como a de uma organização multicultural, cujo clima institucional reflita a valorização da pluralidade de vozes e identidades, e que busque, no confronto de idéias e na orquestração das diferenças, a seiva do trabalho acadêmico e da pesquisa na formação de professores.

\section{Referências}

AGUIAR, N. M. C. B.; CANEN, A. Impactos de políticas de avaliação institucional: um estudo de caso no sistema de ensino naval brasileiro. Ensaio: avaliação e políticas públicas em educação, Rio de Janeiro, v. 15, n. 54, p. 53-66, jan./mar. 2007.

ANDRÉ, M. (Org.). O papel da pesquisa na formação e na prática dos professores. São Paulo: Papirus, 2001.

BINZER, I. V. Os meus romanos: alegrias e tristezas de uma educadora alemã no Brasil. 6. ed. rev. Rio de Janeiro: Paz e Terra, 1994.

CANEN, A. Avaliando a avaliação a partir de uma perspectiva multicultural. Educação Brasileira: revista do CRUB, Brasília, DF, v. 27, n. 54, p. 95-114, jan./ jun. 2005.

CANEN, A. Multiculturalism and a research perspective in initial teacher education: possible dialogues. Policy Futures in Education, Oxford, UK, v. 5, p. 519-534, 2007.

CANEN, A. Novos olhares sobre a produção científica em educação superior: contribuições do multiculturalismo. In: MACEDO, D.; FÁVERO, M. L. A. (Org.). Universidade: políticas, avaliação e trabalho docente. São Paulo: Cortez, 2004.

CANEN, A.; ANDRADE, L. T. Construções discursivas sobre pesquisa em educação: o que dizem professores formadores universitários, Educação e Realidade, Porto Alegre, v. 30, n. 1, p. 49-65, 2005.

CANEN, A.; CANEN, A. G. Rompendo fronteiras curriculares: o multiculturalismo na educação e outros campos de saber, Currículo sem Fronteiras [S.I.], v. 5, n. 2, p. 40-49, 2005a. 
CANEN, A.; MOREIRA, A. F. B. Ênfases e omissões no currículo. São Paulo: Papirus, 2001.

CANEN, A.; OLIVEIRA, A. M. A. Multiculturalismo e currículo em ação: um estudo de caso. Revista Brasileira de Educação, Rio de Janeiro, n. 21, p. 61 $74,2002$.

CANEN, A.; SANTOS, A. R. Construção e reconstrução multicultural de identidades docentes: pensando na formação continuada de coordenadores pedagógicos. Revista Brasileira de Estudos Pedagógicos, Brasília, DF, v. 87, p. 333-344, 2006.

CANEN, A.; XAVIER, G. P. M. Multiculturalismo, pesquisa e formação de professores: o caso das diretrizes curriculares para a formação docente. Ensaio: avaliação e políticas públicas em educação, Rio de Janeiro, v. 13, n. 48, p. 333344, 2005.

CANEN, A. G.; CANEN, A. Organizações multiculturais. Rio de Janeiro: Ciência Moderna, 2005b.

CANEN, A.; XAVIER, L. N. Multiculturalismo, memória e história da educação brasileira: reflexões a partir do olhar de uma educadora alemã no Brasil Imperial. In: MIGNOT, A. C. V.; BASTOS, M. H. C.; CUNHA, M. T. S. (Org.). Refúgios do Eu. Florianópolis: Ed. Mulheres, 2000.

CHARLOT, B. A pesquisa educacional entre conhecimentos, políticas e práticas: especificidades e desafios de uma área do saber. Revista Brasileira de Educação, Rio de Janeiro, v. 11, n. 31, p. 7-18, 2006.

DENZIN, N. K.; LINCOLN, Y. (Ed.). The discipline and practice of qualitative research. In: . (Ed.), Handbook of qualitative research. London: Sage, 2000.

FÁVERO, M. L. A.; SEGENREICH, S. C. D. (Org.). Universidade, ciência e tecnologia (1985-2000): algumas questões. In: MACEDO, D.; FÁVERO, M. L. A. (Org.). Universidade: políticas, avaliação e trabalho docente. São Paulo: Cortez, 2004.

FONSECA, M. V. A arte de construir o invisível: o negro na historiografia educacional brasileira. Revista Brasileira de História da Educação, Curitiba, n. 13, p. 11-50, jan./abr. 2007.

LÜDKE, M.(Org.). O professor e a pesquisa. São Paulo: Papirus, 2001.

Recebido em: 25/02/2008

Aceito para publicação em: 24/03/2008 